\title{
Pemodelan Penggunaan E-Money Pada E-Parking Kota Makassar
}

\author{
Hisyam Ihsan ${ }^{1, a)}$, Syafruddin Side ${ }^{1, b)}$, dan Emi Wulandari ${ }^{1, c)}$ \\ ${ }^{1}$ Jurusan Matematika, Fakultas MIPA, Universitas Negeri Makassar \\ a) hisyamihsan@unm.ac.id \\ b) syafruddin@unm.ac.id \\ c)emiwulandari12@gmail.com
}

\begin{abstract}
Abstrak. Penelitian ini bertujuan untuk membangun model penggunaan E-Money pada E-Parking tipe SIRI (Susceptible - Infected - Recovered - Infected) di Kota Makassar. Asumsi yang ditambahkan adalah manusia yang telah menggunakan E-Money dapat kembali menggunakan uang tunai pada pembayaran parkir. Model ini dibagi menjadi tiga kelas yaitu rentan/berpotensi menggunakan parkir, pengguna uang tunai, dan pengguna E-Money. Data yang digunakan adalah data primer yang diperoleh dengan survey langsung dilapangan. Survey dilakukan dengan membagikan angket kepada 100 responden secara acak. Model matematika tipe SIRI digunakan untuk menentukan titik equilibrium. Hasil simulasi model tipe SIRI menghasilkan bilangan reproduksi dasar $\left(R_{0}\right)$ sebesar 0.021021 yang berarti bahwa penggunaan uang tunai dapat mengalami penurunan yang menyebabkan penggunaan E-Money akan meningkat dalam kurun waktu tertentu.
\end{abstract}

Kata Kunci: Titik Equilibrium, Bilangan Reproduksi Dasar, Uang Elektronik, Parkiran Elektronik, Model SIRI

Abstrack. This study aims to build a model of the use of E-Money in E-Parking type SIRI (Susceptible Infected - Recovered - Infected) in Makassar City. The added assumption is that people who have used EMoney can may return to cash payments on parking. This model is divided into three classes, namely vulnerable / potentially using parking, cash users, and E-Money users. The data used are primary data obtained by direct survey in the field. The survey was conducted by distributing questionnaires to 100 respondents randomly. The SIRI type mathematical model is used to determine the equilibrium point. The simulation results of the SIRI type model produce a base reproduction number $\left(R_{0}\right)$ of 0.021021 which means that the use of cash can decrease which causes the use of E-Money will increase in a certain period of time.

Keywords: Equilibrium Point, Basic Reproduction Numbers, E-Money, E-Parking, SIRI Model

\section{PENDAHULUAN}

Bidang matematika turut memberikan peranan dalam menganalisis dan memodelkan suatu peristiwa atau permasalahan. Model matematika merupakan salah satu alat yang dapat membantu mempermudah penyelesaian masalah dalam kehidupan nyata. Peristiwa atau permasalahan yang dimodelkan akan membentuk suatu model matematika baik dalam bentuk persamaan, pertidaksamaan, sistem persamaan dan bentuk yang lainnya (Lujeng, 2014).

Pemodelan matematika didefinisikan sebagai penggambaran fenomena dunia nyata melalui bahasa/simbol matematis. Pemodelan matematika dapat digunakan untuk menjelaskan perilaku fenomena alam maupun sosial yang terjadi sehingga dapat memprediksi perilaku dari sistem pada 
suatu jangka waktu tertentu. Selain itu juga dapat digunakan untuk mengambil suatu keputusan atau kebijakan terkait dengan permasalahan yang dimodelkan. Salah satu contohnya yaitu aplikasi untuk mengetahui prediksi fenomena penggunaan E-Money (Uang Elektronik).

Beberapa tahun terakhir, pengguna E-Money di Indonesia terus meningkat. Peningkatan tidak saja terjadi pada transaksi E-Money melalui kartu, tetapi melalui operator seluler yang juga marak digunakan. Data Bank Indonesia (BI) per Juni 2017 mencatat terdapat 23 penerbit E-Money, yang terdiri dari 11 Bank dan 12 Lembaga Selain Bank. Berdasarkan data yang tercatat oleh Bank Indonesia, jumlah E-Money yang telah beredar per April 2017 mencapai 57,768,225 E-Money dengan total jumlah transaksi Rp7,06 triliun ditahun 2016 (KPMG Siddharta Advisory, 2017).

Mengingat telah banyak jumlah bank di Sulawesi Selatan yang sadar akan layanan keuangan, sehingga diharapkan bahwa dorongan penggunaan E-Money menjadi lebih efektif. Salah satu tahap awal yang dilakukan untuk mengefektifkan penggunaan E-Money yaitu dengan melakukan elektronifikasi pada Toll. Setelah elektronifikasi Toll yang dilakukan telah berhasil, selanjutnya dilakukan elektronifikasi di perparkiran.

Elektronifikasi pada parkiran (E-Parking) resmi diopersikan di Kota Makassar pada tanggal 11 Maret 2019. Sebanyak 25 unit mesin Terminal Parkir Elektronik (TPE) disebar di tiga titik yaitu, 10 unit di Jalan Somba Opu, 11 unit di Jalan Penghibur dan 4 unit di Jalan Kartini. Selain untuk mendorong penggunaan E-Money, Wali Kota Makassar, Moh Ramdhan Pomanto mengatakan bahwa penerapan mesin TPE ini dilakukan sebagai salah satu upaya untuk meningkatkan Pendapatan Asli Daerah (PAD) Kota Makassar (Sulselsatu, 2019).

Penelitian yang membahas mengenai penggunaan E-Parking sudah dilakukan oleh beberapa peneliti. Penelitian yang dilakukan adalah terkait penggunaan mesin parkir elektronik sebagai wujud smart city yang telah dilakukan oleh Kireina (2017). Selain itu, terdapat penelitian terkait efektivitas program Terminal Parkir Elektronik (TPE) yang telah dilakukan oleh Pradipta \& Hariani (2017).

Penelitian ini menggabungkan antara pemodelan matematika dibidang kesehatan dan penelitian dibidang ekonomi. Beberapa pemodelan matematika telah dilakukan dalam bidang ekonomi (Caraka, Yasin, \& Prahutama, 2015; Fadhilah, Suparti, \& Tarno, 2016; Permatasari, Warsito, dan Sugito, 2014; Susanto \& Adianto, 2005; Shina, 2016; Saputri, Suparti, \& Hoyyi, 2015; Putri \& Ratnasari, 2016; Hidayat \& Sudarsono, 2016). Dalam menjelaskan kondisi ekonomi dari suatu negara, Permatasari, dkk, (2014) menggunakan model Markov Switching Vektor Autoregressive (Msvar). Selain itu, Fadhilah, dkk, (2016) menggunakan model regresi spline truncated untuk data longitudinal dalam penentuan harga saham.

Pada pemodelan matematika di bidang ekonomi belum banyak ditemukan yang menggunakan pembagian kelas pada populasi sebagai langkah awal dalam membangun suatu model. Pembagian kelas tersebut telah banyak dilakukan pada bidang kesehatan dalam memodelkan penyebaran suatu penyakit. Beberapa peneliti telah mengkaji pemodelan matematika pada bidang kesehatan dengan pembagian kelas (Side, 2015; Awaliya, 2016; Fadilah \& Zulakmal, 2016; Side, Sukarna \& Asfarina, 2018).

Penelitian yang dilakukan oleh Desyanawati (2016) membagi populasi menjadi 3 kelas menggunakan model SIR (Susceptible, Infected, Removed) dalam mensimulasikan penyebaran HIV/AIDS. Selain itu, Side (2015) mensimulasikan penyebaran Tuberculosis dengan membagi populasi menjadi 3 kelas menggunakan model SIR (Susceptible-Infected-Recovered).

Pada penelitian ini dilakukan modifikasi model SIR yang biasa digunakan pada bidang kesehatan dalam penentuan kelas pada populasi. Tujuan penelitian ini untuk membangun model Penggunaan E-Money pada E-Parking tipe SIRI (Susceptible - Infected - Recovered - Infected) di Kota Makassar. Model yang dibangun menambahkan asumsi bahwa manusia yang telah menggunakan E-Money dapat kembali menggunakan uang tunai pada pembayaran parkir. 


\section{HASIL DAN PEMBAHASAN}

\section{Hasil}

\section{Model SIRI Penggunaan E-Money pada E-Parking Kota Makassar}

Pada model ini populasi total $(\mathrm{N})$ dibagi menjadi empat kelas yaitu kelas Susceptible $(\mathrm{S}(\mathrm{t}))$ menyatakan kelas yang berpotensi menggunakan parkir, kelas Infected $(\mathrm{I}(\mathrm{t}))$ menyatakan kelas pengguna parkir yang melakukan pembayaran tunai, dan kelas Recovered $(\mathrm{R}(\mathrm{t})$ ) menyatakan pengguna parkir yang melakukan pembayaran menggunakan E-Money. Formulasi model dalam penelitian ini menambahkan asumsi bahwa manusia yang telah menggunakan E-Money dapat kembali menggunakan uang tunai pada pembayaran parkir akibat hilangnya kartu $E$-Money $(\theta)$ dan kehabisan saldo kartu E-Money $(\beta)$.

Model untuk Penggunaan E-Money pada E-Parking Kota Makassar dalam bentuk diagram transfer sebagaimana Gambar 1.

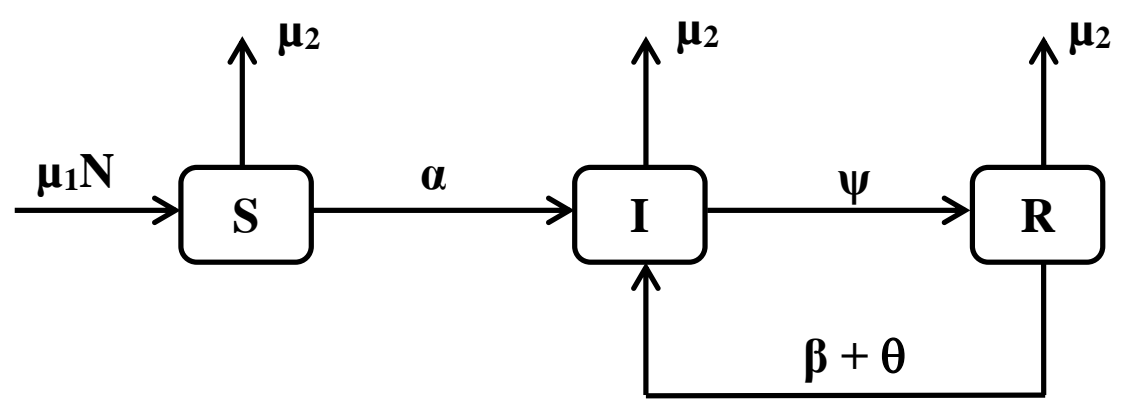

GAMBAR 1. Diagram Transfer Model SIRI Penggunaan E-Money pada E-Parking Kota

Makassar

Variabel dan parameter yang digunakan dalam Model SIRI Penggunaan E-Money pada E-Parking Kota Makassar didefinisikan dalam Tabel 1.

TABEL 1. Penjelasan Variabel/Parameter

\begin{tabular}{cl}
\hline Variabel/Parameter & \multicolumn{2}{c}{ Definisi } \\
\hline $\mathrm{S}($ Susceptible $)$ & Pengguna yang berpotensi menggunakan parkir \\
$\mathrm{I}$ (Infected) & Pengguna parkir yang melakukan pembayaran tunai \\
$\mathrm{R}$ (Recovered) & Pengguna parkir yang telah melakukan pembayaran \\
$\mathrm{N}$ & menggunakan E-Money \\
$\mu_{1}$ & Total populasi orang yang berusia 17 tahun keatas \\
$\mu_{2}$ & Laju pengguna yang dapat mengendarai kendaraan \\
$\alpha$ & Laju pengguna yang tidak memiliki kendaraan \\
$\psi$ & Laju pengguna parkir yang tidak memiliki E-Money \\
$\beta$ & Laju pengguna parkir yang telah memiliki E-Money \\
$\theta$ & Laju pengguna parkir kehabisan saldo E-Money \\
\hline
\end{tabular}

Formulasi untuk model pada Gambar 1 setelah melakukan penyederhanaan dituliskan dalam bentuk Persamaan (1), (2), dan (3).

$$
\begin{gathered}
\frac{d S}{d t}=\mu_{1}-\left(\mu_{2}+\alpha\right) S \\
\frac{d I}{d t}=\alpha S+(\beta+\theta) R-\left(\mu_{2}+\psi\right) I \\
\frac{d R}{d t}=\psi I-\left(\mu_{2}+\beta+\theta\right) R
\end{gathered}
$$


dengan $N=(S(t))+(I(t))+(R(t))$ adalah total populasi

\section{Titik Equilibrium dan Analisis Kestabilannya}

\section{Titik Equilibrium Bebas Tunai $\left(E_{0}\right)$}

Titik equilibrium bebas tunai terjadi pada saat $\left(\frac{d S}{d t}, \frac{d E}{d t}, \frac{d I}{d t}, \frac{d R}{d t}\right)=(0,0,0,0)$. Berdasarkan persamaan (1) dapat ditentukan titik equilibrium bebas tunai melalui persamaan (4), (5), dan (6).

$$
\begin{gathered}
\mu_{1}-\left(\mu_{2}+\alpha\right) S=0 \\
\alpha S+(\beta+\theta) R-\left(\mu_{2}+\psi\right) I=0 \\
\psi I-\left(\mu_{2}+\beta+\theta\right) R=0
\end{gathered}
$$

Titik equilibrium bebas tunai $\left(\mathrm{E}_{0}\right)$ diperoleh dengan mengasumsikan $\mathrm{I}=0$, sehingga diperoleh suatu keadaan bahwa semua individu masuk ke populasi Susceptible dan Recovered serta tidak ada individu yang melakukan pembayaran secara tunai sehingga sadar tentang penggunaan $E$ Money.

Berdasarkan Persamaan (4) diperoleh $S=\frac{\mu_{1}}{\mu_{2}+\alpha}$

Berdasarkan Persamaan (6) diperoleh $R=0$

Jadi titik equilibrium bebas tunai $\mathrm{E}_{0}=\left(\frac{\mu_{1}}{\mu_{2}+\alpha}, 0,0\right)$

\section{Titik Equilibrium Pembayaran Tunai $\left(E_{1}\right)$}

Titik equilibrium pembayaran tunai terjadi dengan memisalkan $\mathrm{E}_{1}\left(\mathrm{~S}^{*}, \mathrm{I}^{*}, \mathrm{R}^{*}\right)$ dan dapat diketahui dengan mengasumsikan $I \neq 0$. Berdasarkan Persamaan (4), (5), dan (6) dilakukan proses penyederhanaan sistem sehingga diperoleh

$S^{*}=\frac{\mu_{1}}{\mu_{2}+\alpha}$

$I^{*}=\frac{\alpha \mu_{1}\left(\beta+\theta+\mu_{2}\right)}{\left(\beta+\theta+\mu_{2}+\psi\right) \mu_{2}\left(\mu_{2}+\alpha\right)}$

$R^{*}=\frac{\varepsilon \alpha \mu_{1}}{\left(\mu_{2}+\beta+\theta+\psi\right)\left(\mu_{2}\right)\left(\mu_{2}+\alpha\right)}$

Jadi titik equilibrium pembayaran tunai $E_{1}=\left(\frac{\mu_{1}}{\mu_{2}+\alpha}, \frac{\alpha \mu_{1}\left(\beta+\gamma+\mu_{2}\right)}{\left(\beta+\gamma+\mu_{2}+\psi\right) \mu_{2}\left(\mu_{2}+\alpha\right)}, \frac{\psi \alpha \mu_{1}}{\left(\mu_{2}+\beta+\gamma+\psi\right)\left(\mu_{2}\right)\left(\mu_{2}+\alpha\right)}\right)$.

\section{Analisis Kestabilan}

Analisis kestabilan dilakukan dengan menentukan matriks Jacobian dengan linearisasi pada sekitar titik equilibrium bebas tunai yang ada pada model SIRI. Matriks Jacobian yang diperoleh setelah melakukan pelinearan adalah sebagai berikut.

$$
J E_{0}=\left[\begin{array}{ccc}
-\left(\mu_{2}+\alpha\right) & 0 & 0 \\
\alpha & -\left(\mu_{2}+\psi\right) & \beta+\theta \\
0 & \psi & -\left(\beta+\theta+\mu_{2}\right)
\end{array}\right]
$$


Kestabilan $\mathrm{E}_{0}$ dapat diperoleh dengan terlebih dahulu mencari nilai eigen matriks tersebut. Jika $\lambda \mathrm{I}$ adalah nilai eigen $J E_{0}$ maka $\operatorname{det}\left(\lambda I-J E_{0}\right)=0$. Setelah menyederhanakan hasil determinan diperoleh persamaan (7).

$$
\begin{array}{r}
0=\lambda^{3}+\lambda^{2}\left(3 \mu_{2}+\psi+\alpha+\beta+\theta\right)+\lambda\left(3 \mu_{2}{ }^{2}+2 \mu_{2} \psi+2 \alpha \mu_{2}+\alpha \psi+\alpha \beta+\alpha \theta+\right. \\
\left.2 \beta \mu_{2}+2 \theta \mu_{2}\right)+\left(\mu_{2}{ }^{3}+\mu_{2}{ }^{2} \beta+\mu_{2}{ }^{2} \psi+\mu_{2}{ }^{2} \alpha+\mu_{2}{ }^{2} \theta+\mu_{2} \alpha \beta+\mu_{2} \alpha \psi+\mu_{2} \alpha \theta\right)
\end{array}
$$

Dengan menggunakan aplikasi Maple diperoleh nilai eigen sebagai berikut.

$\lambda_{1}=-\alpha-\mu_{2}=-\left(\alpha+\mu_{2}\right)$

$\lambda_{2}=-\mu_{2}$

$\lambda_{3}=-\theta-\beta-\psi-\mu_{2}=-\left(\theta+\beta+\psi+\mu_{2}\right)$

Berdasarkan nilai eigen yang telah diperoleh maka titik equilibrium stabil asimtot karena semua nilai eigen $\lambda$ (akar karakteristik) adalah real negatif.

\section{Bilangan Reproduksi Dasar $\left(\mathbf{R}_{0}\right)$}

Bilangan reproduksi dasar dari penggunaan E-Money diperoleh dengan terlebih dahulu menentukan nilai eigen dari matriks Jacobian dari suatu sistem persamaan yang dihitung pada titik equlibrium bebas tunai. Berdasarkan Persamaan (7) diperoleh $\mathrm{R}_{0}$ dari bagian konstannya yaitu sebagai berikut.

$$
\begin{gathered}
\mu_{2}{ }^{3}+\mu_{2}{ }^{2} \beta+\mu_{2}{ }^{2} \psi+\mu_{2}{ }^{2} \alpha+\mu_{2}{ }^{2} \theta+\mu_{2} \alpha \beta+\mu_{2} \alpha \psi+\mu_{2} \alpha \theta=0 \\
R_{0}=\mu_{2}{ }^{3}+\mu_{2}{ }^{2} \beta+\mu_{2}{ }^{2} \psi+\mu_{2}{ }^{2} \alpha+\mu_{2}{ }^{2} \theta+\mu_{2} \alpha \beta+\mu_{2} \alpha \psi+\mu_{2} \alpha \theta
\end{gathered}
$$

\section{Simulasi Model}

Simulasi dilakukan menggunakan program Maple 18 dan dengan memberikan nilai-nilai untuk masing-masing data awal dan parameter. Nilai-nilai data awal diperoleh dari jumlah responden yang diberikan angket dan disajikan pada Tabel 2.

TABEL 2. Data Awal

\begin{tabular}{cc}
\hline Variable & Nilai \\
\hline $\mathrm{S}(0)$ & 10 \\
$\mathrm{I}(0)$ & 62 \\
$\mathrm{R}(0)$ & 28 \\
$\mathrm{~N}(0)$ & 100 \\
\hline
\end{tabular}

TABEL 3. Parameter Model SIRI penggunaan E-Money pada E-Parking

\begin{tabular}{ccc}
\hline Parameter & $\begin{array}{c}\text { Nilai Parameter 1 } \\
\text { (Data Asli) }\end{array}$ & $\begin{array}{c}\text { Nilai Parameter 2 } \\
\text { (Uji Parameter lain) }\end{array}$ \\
\hline$\mu_{1}$ & 0.97 & 0.97 \\
$\mu_{2}$ & 0.07 & 0.07 \\
$\alpha$ & 0.7 & 0.3 \\
$\psi$ & 0.3 & 0.7 \\
$\beta$ & 0 & 0 \\
$\theta$ & 0.02 & 0.02 \\
\hline
\end{tabular}


Parameter-parameter yang digunakan pada model terdiri atas 2 jenis. Parameter jenis pertama (Parameter I) berupa data primer yang diperoleh dari hasil penyebaran angket dilokasi penelitian. Sedangkan parameter jenis kedua (Parameter 2) berupa parameter lain yang digunakan sebagai pembanding dari parameter 1. Berikut Nilai paramaeter disajikan pada Tabel 3.

Parameter yang telah diperoleh selanjutnya disubstitusi ke persamaan (1) sehingga didapatkan formulasi model SIRI penggunaan E-Money pada E-Parking Kota Makassar sebagai berikut.

$$
\begin{aligned}
& \frac{d S}{d t}=(0.97)-(0.07 S+0.3) S \\
& \frac{d I}{d t}=0.3 S+(0+0.02) R-(0.07+0.7) I \\
& \frac{d R}{d t}=0.7 I-(0.07+0+0.02) R
\end{aligned}
$$

Simulasi model penggunaan E-Money pada E-Parking Kota Makassar dilakukan setelah melakukan analisis model, identifikasi variabel, dan pengambilan data. Adapun hasil simulasi Studi kasus penggunaan E-Money pada E-Parking Kota Makassar menggunakan data awal dan nilai parameter disajikan pada Gambar 2.

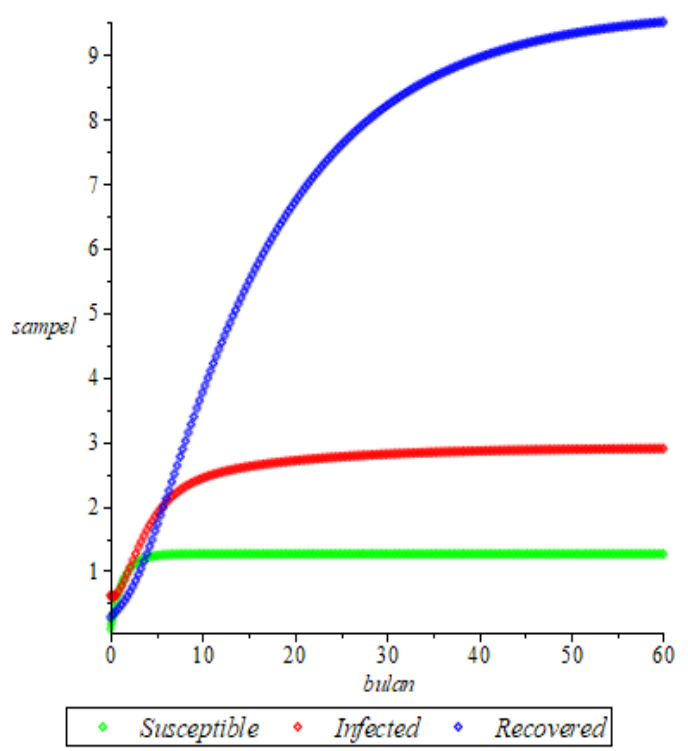

(a) Parameter 1

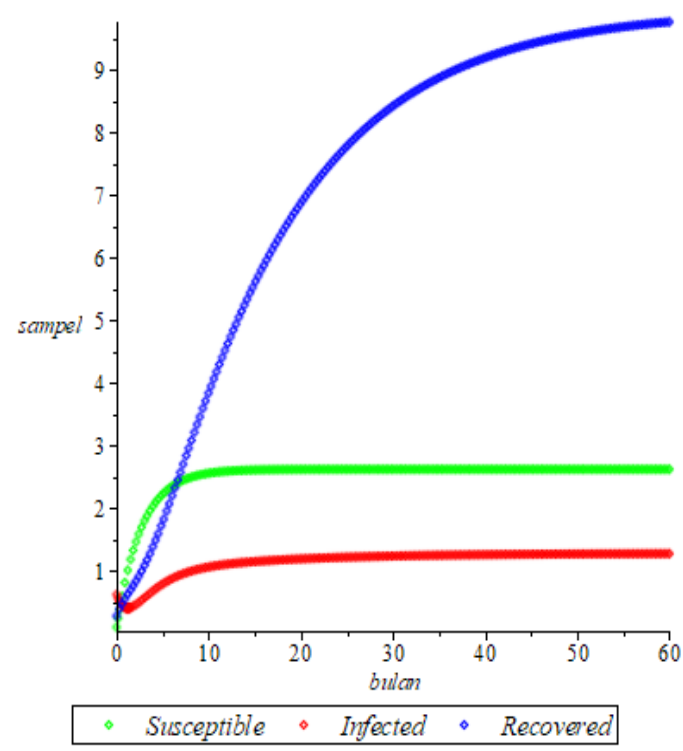

(b) Parameter 2

GAMBAR 2. Kurva model penggunaan E-Money pada E-Parking Kota Makassar

Gambar 2(a) menjelaskan kurva model penggunaan E-Money pada E-Parking Kota Makassar dengan menggunakan nilai dari parameter 1 yang berupa data primer dari hasil penyebaran angket di lokasi penelitian. Gambar 2(a) menunjukkan bahwa penggunaan E-Money pada E-Parking memerlukan waktu lebih dari 5 bulan untuk melebihi jumlah pengguna tunai dan jumlah populasi pada kelas Infected mengalami kenaikan yang lebih tinggi dibandingkan kelas Susceptible.

Gambar 2(b) menjelaskan kurva model penggunaan E-Money pada E-Parking Kota Makassar dengan menggunakan nilai dari parameter 2 yang digunakan untuk membandingkan dengan parameter data primer yang diperoleh dari hasil penyebaran angket. Gambar 2(b) menunjukkan bahwa penggunaan E-Money pada E-Parking hanya memerlukan waktu kurang dari 5 bulan untuk melebihi jumlah pengguna tunai. Selain itu jumlah populasi pada kelas Susceptible mengalami kenaikan yang lebih tinggi dibandingkan kelas Infected. 


\section{Pembahasan}

Penelitian terdahulu yang telah dilakukan oleh Penelitian Side (2015) memperoleh model SIR dimana populasi dibagi menjadi tiga kelas yaitu Susceptible, Infected, dan Recovered dengan memperhatikan transmisi dari populasi dan mendapatkan hasil bahwa semakin menurun nilai parameter yang digunakan maka Susceptible dan Infected semakin meningkat sementara Recovered mengalami penurunan seiring berjalannya waktu.

Penelitian Desyanawati (2016) memperoleh hasil simulasi penyebaran penyakit HIV/AIDS yang dimodelkan menggunakan model Susceptible, Infected, dan Removed (SIR) dengan mengubah kelas Removed menjadi kelas AIDS Cases. Simulasi digunakan untuk mengetahui penyebaran jumlah kasus HIV dan daerah berpotensi endemik yang divisualisasikan dalam peta provinsi Jawa Tengah.

Penelitian ini menggabungkan dua bidang yaitu bidang sains (Pemodelan matematika) dan bidang ekonomi (Penggunaan E-Money). Model yang terbentuk berasal dari modifikasi model yang telah dilakukan pada penelitian Side (2015) dan Desyanawati (2016). Model tersebut dimodifikasi menjadi model SIRI dengan membuat asumsi-asumsi baru sesuai dengan bidang yang diteliti dan menambahkan parameter yang menyebabkan pengguna dapat kembali menjadi kelas Infected setelah sebelumnya berada dikelas Recovered.

Pada penelitian ini data yang digunakan untuk simulasi berupa data primer yang diperoleh dari hasil penyebaran angket penelitian di 3 wilayah Makassar yang terdapat mesin Terminal Parkir Elektronik (TPE) yaitu di Jl. RA Kartini, Jl. Somba Opu, dan Jl. Penghibur. Hasil simulasi diperoleh bahwa penggunaan E-Money pada E-Parking memerlukan waktu lebih dari 5 bulan untuk mencapai jumlah yang lebih tinggi dari jumlah pengguna tunai dan jumlah populasi pada kelas Susceptible akan menetap (konstan).

\section{KESIMPULAN}

Penggunaan E-Money pada E-Parking berbentuk diagram transfer kemudian dibentuk menjadi persamaan differensial yaitu

$$
\begin{aligned}
& \frac{d S}{d t}=\mu_{1}-\left(\mu_{2}+\alpha\right) S \\
& \frac{d I}{d t}=\alpha S+(\beta+\theta) R-\left(\mu_{2}+\psi\right) I \\
& \frac{d R}{d t}=\psi I-\left(\mu_{2}+\beta+\theta\right) R
\end{aligned}
$$

Analisis kestabilan bilangan reproduksi dasar $\left(\mathrm{R}_{0}\right)$ model penggunaan E-Money pada E-Parking kota Makassar diperoleh nilai sebesar 0.021021 yang berarti bahwa seseorang yang melakukan pembayaran tunai tidak akan menyebabkan orang lain ikut melakukan pembayaran tunai sehingga penggunaan uang tunai pada parkiran dapat mengalami penurunan yang menyebabkan penggunaan E-Money pada E-Parking kota Makassar akan meningkat dalam kurun waktu tertentu.

Hasil simulasi model penggunaan E-Money pada E-Parking kota Makassar bahwa penggunaan E-Money pada E-Parking memerlukan waktu lebih dari 5 bulan untuk mencapai jumlah yang lebih tinggi dari jumlah pengguna tunai dan jumlah populasi pada kelas Susceptible akan menetap (konstan). 


\section{DAFTAR PUSTAKA}

Awaliya, W. N. (2016). Model SEIR pada Penyakit Tuberkulosis di Kabupaten Bulukumba (Skripsi). Universitas Negeri Makassar, Indonesia.

Caraka, R.E., Yasin, H. \& Prahutama, A. (2015). Pemodelan General Regression Neural Network (grnn) pada Data Return Indeks Harga Saham Euro 50. Jurnal Gaussian, 4(2). 181-192.

Desyanawati, E. (2016). Simulation on the Spreading of Infectious Disease HIV/AIDS in Central Java Using SIR Epidemic Model (Susceptible, Infected, Removed). ITsmart: Jurnal Ilmiah Teknologi dan Informasi, 5.

Desyanawati, E. (2016). Simulation on the Spreading of Infectious Disease HIV/AIDS in Central Java Using SIR Epidemic Model (Susceptible, Infected, Removed). ITsmart: Jurnal Ilmiah Teknologi dan Informasi, 5(2).

Fadilah, F. H., \& Zulakmal. (2016). Kajian Perilaku Model Matematika Penularan Penyakit Tuberkulosis. Jurnal Matematika UNAND, 5(2). 26-32.

Fadhilah, K.N., Suparti, S. \& Tarno, T. (2016). Pemodelan Regresi Spline Truncated untuk Data Longitudinal (Studi Kasus: Harga Saham Bulanan pada Kelompok Saham Perbankan Periode Januari 2009- Desember 2015). Jurnal Gaussian, 5(3). 447-454.

Hidayat, M.A. \& Sudarsono, B. (2016). Pemodelan Pertumbuhan Tata Ruang Kota Makassar Berdasarkan Aspek Ekonomi Menggunakan Konsep Analisis Spasial Citra Satelit Resolusi Tinggi. Jurnal Geodesi Undip, 5(3). 61-69.

Kireina, N.F. (2017). Mesin Parkir Elektronik Sebagai Wujud Dari Smart City Di Kota Bandung. Journal of JISPO : Jurnal Ilmu Sosial Dan Ilmu Politik.

KPMG Siddharta Advisory. (2017). Retail Payments in Indonesia: Who will drive the cashless revolution?. https://assets.kpmg.com/content/dam/kpmg/id/pdf/2017/01/id-retailpayments-in-indonesia.pdf.

Lujeng. (2014). Pengertian Pemodelan Matematika. http://matematikalujeng.blogspot.co.id/2014/04/pengertian-pemodelan matematika.html

Permatasari, H., Warsito,B. \& Sugito, S. (2014). Pemodelan Markov Switching Vektor Autoregressive (Msvar). Jurnal Gaussian, 3(3). 421-430.

Putri, R.C. \& Ratnasari, V. (2016). Pemodelan Logit, Probit dan Complementary Log-Log Pada Studi Kasus Partisipasi Perempuan Dalam Pembangunan Ekonomi di Kalimantan Selatan. Jurnal Sains dan Seni, 4(2).

Pradipta, R. \& Hariani, D. (2017). Efektivitas Program Terminal Parkir Elektronik (TPE) di DKI Jakarta (Studi Kasus Jalan H. Agus Salim atau Jalan Sabang Jakarta Pusat). Journal of Public Policy and Management Review.

Saputri, K.H., Suparti, S. \& Hoyyi, A. (2015). Pemodelan Kurs Rupiah Terhadap Dollar Amerika Serikat Menggunakan Regresi Penalized Spline Berbasis Radial. Jurnal Gaussian, 4(3). 433-541.

Shina, A.F.I. (2016). Penerapan 2 SLS GMM-AB pada Persamaan Simultan Data Panel Dinamis untuk Pemodelan Pertumbuhan Ekonomi Indonesia Sebagai Islamic Country. Jurnal Ekonomi dan Perbankan Syariah, 7(1). 141-162.

Side, S. (2015). A Susceptible-Infected-Recovered Model and Simulation for Transmission of Tuberculosis. Jurnal American Scientific Publishers, 21(2). 137-139.

Side, S., Sukarna., \& Asfarina. G. T. (2018). Analisis Kestabilan Penyebaran Kelera Menggunakan Model SEIRS dengan Vaksinasi dan Faktor Treatment. Journal of mathematics, and Statistics, 1(2). 155-168. 
Ihsan, Side, \& Wulandari

Sulselsatu. (2019). Parkir di Makassar Kini Gunakan E-Money. https://www.sulselsatu.com/wpcontent/uploads/2019/03/IMG-20190311-WA0049.jpg.

Susanto, S. Adianto, H. (2005). Pemodelan dan Penyelesaian Pemrograman Linear dengan Koefisien Fungsi Objektif Berbentuk Bilangan Kabur Segitiga. Universitas Gunadarma. 